\title{
The Effect of Emotional Intelligence on Turnover Intentions; The Role of Employee Well-being, Engagement and Perceived Organizational Support
}

\author{
M. Waheed Akhtar, Hafiz Ghufran, Tasneem Fatima* \\ International Islamic University, Islamabad
}

\begin{abstract}
This study investigated the mediating role of employee well-being and engagement in the relationship between emotional intelligence and turnover intentions. It also investigated the interactional effect of perceived organizational support in the relationship between emotional intelligence and mediators (employee well-being and engagement). Stratifying simple random sampling technique was used for data collection. 450 questionnaires were distributed among the employees of different banks at Islamabad and Rawalpindi. Data were analyzed through reliability testing, correlation and regression analysis. The results showed that employee well-being and engagement mediate the relationship between emotional intelligence and turnover intentions; whereas, perceived organizational support positively moderates the relationship between emotional intelligence and mediators as well. Managerial implication, limitation and direction for future studies are included in the paper.
\end{abstract}

\section{Introduction}

Researchers from psychology, HRM and OB are focusing on studies related to emotional intelligence (Mayer et al., 2003). In management studies emotional intelligence is the predictor of organizational outcomes (Jordan and Troth, 2011). Emotional intelligence defined as "the ability to monitor one's own and others' feelings and emotions, to discriminate among them and to use this information to guide one's thinking and actions" (Salovey and Mayer, 1990). Bande et al. (2015) stated that emotions are the intrinsic part of workplace but very fewer studies investigated the emotions at workplace. Whereas, in competitive environment organizations need employees and leaders who work effectively, are adaptive in nature, customer focused and constantly focusing on the improvement of process and system.

The level of emotional intelligence (EI) of employees refers to their own perception about their own emotional skills and abilities, personality traits and behavior that help them in managing themselves according to environmental pressure and demands. Many researchers investigated the effect of emotional intelligence on organizational work related outcomes, such as, job performance, job satisfaction, turnover intentions, turnover (Sy et al., 2006; Trivellas et al., 2011). Low level of stress, anxiety, burnout, turnover and well-being is associated with higher level of emotional intelligence (Karimi et al., 2014; Nikolaou and Tsaousis, 2002; Por et al., 2011; Slaski and Cartwright, 2003;

*Corresponding author.

Email: tasneem.fatima@iiu.edu.pk
Tsaousis and Nikolaou, 2005).

In today's environment organizations focus on employee's well-being in order to enhance employee satisfaction and help the organizations to flourish, grow and change according to environmental demands enabling organizations to compete at international level (Karimi et al., 2014). Well-being defined as "an employee's quality of life and psychological status at work" (Siegrist and Rödel, 2006). Durán et al. (2004) stated that emotional intelligence enhances the employee's well-being. When employees are emotionally intelligent, then they are more engaged with their work. Saks (2006) defined employee engagement as "an emotional and intellectual commitment to the organization". According to Zhu et al. (2015) employee engagement is an outcome of emotional intelligence.

Their study results showed that when employees perceived support from their organizations to be supportive, they feel more attachment to their organization. Perceived organizational support defined as "employee's perceive their organization either being favorable or unfavorable with the workers and associate it with humanly features" (Eisenberger et al., 1986). Cullen et al. (2014) stated that perceived organizational support has positive impact on job satisfaction and job performance.

In today's global and competitive environment organizations need competent and intelligent employees to meet environmental challenges, and the retention of those competent employees is the main problem in the organizations. Managers with higher emo- 
tional intelligence need high organizational support so that their satisfaction level will be high, leading to decrease in the intention to quit. Many researchers investigated the relationship between emotional intelligence with turnover intentions (Rahim et al., 2015), employees engagement (Mahon et al., 2014; Pena Garrido and Extremera Pacheco, 2012; Zhu et al., 2015) well being (Agrawal and Khan, 2015; Karimi et al., 2015, 2014), and perceived organizational support (Mahon et al., 2014; ?). There exists a gap in EI literature, particularly the literature on the interactional effect of perceived organizational support with EI and dependent variables, i.e. employee well-being and engagement, while the mediating role of both employee well-being and engagement in the relationship between EI and turnover intentions is also understudied. Therefore, current study aims to fill this gap.

Present study will help the managers in banking sector to understand the role of EI related to employee turnover. Secondly, it will help them to understand the role of employee engagement and well-being related to employee turnover. Thirdly, it will also help the managers to understand the role of organizational support and its effect on employee engagement and well-being. Gaining an insight into the emotional intelligence and perceived organizational support would help individuals in both capacities to increase their engagement at individual level.

\section{Literature Review}

\subsection{Emotional intelligence and Turnover Intention}

Emotional intelligence has been an area for concern for the researchers. The research on the subject has evolved through many years dating back to 1990 when first paper on emotional intelligence was published. In 1990, Salovey and Mayer (1990) defined EI as "the ability of an individual to precisely feel emotions, to access and create emotions in order to support thoughts, to appreciate feelings and emotional knowledge, and to thoughtfully control emotions in order to promote emotional and intellectual development".

The research on EI has been primarily based on three theoretical models; i.e. "Ability Model" by Mayer (1997); the Emotional - Social Intelligence Model by Bar-On (1997) and the Emotional Competencies Model presented by Goleman (1998). For the purpose of this study ability Model (Mayer, 1997) will be utilized. Mayer (1997) has described EI as "the ability to perceive accurately, appraise, and express emotions; the ability to access and / or generate feelings when they facilitate thought; the ability to understand emotions and emotional knowledge; and the ability to regulate emotions to promote emotional and intellectual growth". The emotional intelligence theory emphasizes emotional intelligence and the level of job performance of employees. According to this theory, employees with higher emotional intelligence are more satisfied with their job as compared to employees with low emotional intelligence.

Turnover of workforce is defined as "the number of employees that quit within a given time period, usually one year, in relation to the total number of employees" (Sellgren et al., 2007). The intention of workers to leave their current job is both disturbing for managers and organizations for the reason that the employees intending to leave when quitting is a costly affair for the organizations. It requires hiring fresh employees and also adversely affects the services being provided by the organization (Sellgren et al., 2007).

Previous researches established a negative relation between EI and turnover (Carmeli, 2003; Firth et al., 2004; Goleman, 1998; Lee and Liu, 2007). Wong and Law (2002) posited the establishment of negative relationship between emotional intelligence (EI) and turnover intention; thus higher the EI lesser will the employee's intention to quit. According to Mayer (1997) ability model of emotional intelligence, high level of EI employees show high performance; therefore, employees with higher emotional intelligence have very low intentions to quit. Thus, based on the literature it is hypothesized that:

\section{H1. Emotional intelligence is negatively associated with turnover intention.}

\subsection{Employees Well-being as a mediator}

The literature available on psychology and sociology have proposed three categories of wellbeing (Grant et al., 2007), comprising physical, social and psychological wellbeing. Psychological wellbeing is studied as the consequence of the hedonism and the eudemonism (Ryan and Deci, 2001). Hedonism is the feeling of employees about their work in organizations which is measured through employee's job satisfaction (Locke, 1976; Weiss, 2002); whereas, eudemonism refers to employees' perception that they are able to express their abilities (Wrzesniewski et al., 2003).

Employee well-being may be defined as an employee's quality of life and psychological status at work (Siegrist and Rödel, 2006). Many researchers have conceived that employees with higher emotional intelligence are more satisfied with their emotional well-being (Goleman, 1995; Salovey and Mayer, 1990; Salovey et al., 1995) and employees who have more control over their emotions have comparatively better perception of life and are considered emotionally healthier. Many researchers investigated the relationship between EI and well-being, while their study results showed that employees scoring high on emotional 
intelligence are less prone to depression and unhappiness (Schutte et al., 1998), which leads to higher optimism (Schutte et al., 1998) and more satisfaction with life (Ciarrochi et al., 2000). Therefore, based on the literature it is hypothesized that:

\section{H2. Emotional intelligence is positively associated with} employee wellbeing.

Earlier researchers found a link between wellbeing and organizational commitment (Wright and Cropanzano, 2000). According to Brunetto et al. (2012) well-being predicted the police officer's organizational commitment and their intentions to leave current job. Hence it is hypothesized that:

H3. Wellbeing is negatively associated with turnover intention.

The relationship between EI and turnover is justified and supported by above arguments; whereas, wellbeing and turnover intentions relationship is justified through previous research and hypothesized in above section. The mediating role of wellbeing in the relationship between EI and turnover intentions is explained with the help of past studies. Brunetto et al. (2012) examined the effect of emotional intelligence upon the job satisfaction, well-being and engagement of police officers in explaining their organizational commitment and turnover intentions and results revealed that EI predicted police officers' perceptions of well-being and job satisfaction, which influenced engagement and affective commitment and, subsequently, negatively affected turnover intentions. Brunetto et al. (2013) investigated the effect of workplace relationships (perceived organizational support, supervisor' nurse relationships and teamwork) on the engagement, well-being, organizational commitment and turnover intentions of nurses working in Australian and USA hospitals and finding suggested that well-being is a predictor of turnover intentions. Hence it is hypothesized that:

H4. Employee well-being mediates the relationship between EI and turnover intentions.

\subsection{Employee Engagement as a mediator}

Kahn (1990) defined engagement as a work situation where employees find work meaningful, and consequently, they want to, and can invest in their work to achieve personal and career benefits. Saks (2006) defined employee engagement is that as "an emotional and intellectual commitment to the organization". Brunetto et al. (2012) research on police officers showed that emotional intelligence was the motivational factor for employee's engagement with job sat- isfaction and well-being as mediator. In the same way, Pena Garrido and Extremera Pacheco (2012) found that emotional intelligence of teachers was associated with higher levels of engagement. According to Zhu et al. (2015) employee engagement is an outcome of emotional intelligence. Based on the above it can be hypothesized that:

H5. Emotional intelligence is positively associated with employee engagement.

Recently turnover has become an area of concern for organization as it raises the requirement of hiring and later on training new employees (Thanacoody et al., 2014) and for the reason has evolved greater attention to increase the attachment of employees with the parent organization. Employees who are more engaged with their organization stick to their organization (Shuck and Reio Jr, 2014). On the other hand disengaged employees are more likely to quit parent organizations. Literature review suggests that engagement has an inverse relationship with intention to leave (Saks, 2006). This negative association between work engagement and intention to quit is highlighted by SET (Halbesleben, 2010; Rousseau, 1995). Based on this it can hypothesize that:

H6. Employee engagement is negatively associated with turnover intentions.

The relationship between EI and turnover is justified and supported by above arguments; whereas, engagement and turnover intentions relationship is justified through previous research and hypothesized in above section. The mediating role of engagement in the relationship between EI and turnover intentions is explained with the help of past studies. According to Mayer (1997) ability model of emotional intelligence, highly emotionally intelligent employees show high performance so that's why they have high level of engagement. Brunetto et al. (2012) examined the effect of emotional intelligence upon the job satisfaction, wellbeing and engagement of police officers in explaining their organizational commitment and turnover intentions and the results revealed that EI predicted police officers' perceptions of well-being and job satisfaction, which influenced engagement and affective commitment and, subsequently, negatively affected turnover intentions. Therefore, it can be hypothesized that:

H7. Employees engagement mediates the relationship between emotional intelligence and turnover intentions. 


\subsection{Perceived organizational support as a moderator}

Perceived Organizational Support (POS) is an organization environment in which it is perceived that the organization will look after the welfare of its employees (Eisenberger et al., 1986; Loi et al., 2006). This perception of employees about an organization's nature depends on the rules and regulations laid down by the organization and the behavior of its representatives (Eisenberger et al., 1986). The Concept of perceived organizational support suggests that employees' perceive their organization either being favorable or unfavorable with the workers and associate it with humanly features (Eisenberger et al., 1986). Employees with higher emotional intelligence and with perception of higher organizational support have higher wellbeing. Brunetto et al. (2013) investigated the effect of workplace relationships (perceived organizational support, supervisor' nurse relationships and teamwork) on the engagement, well-being, organizational commitment and turnover intentions of nurses working in Australian and USA hospitals and finding suggested that POS is a predictor of well-being.

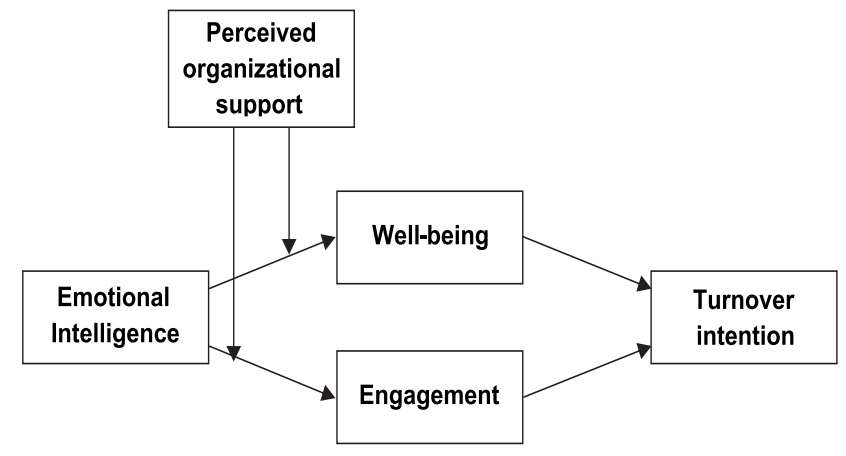

Figure 1: Theoretical framework.

Kurtessis et al. (2015) stated that fewer studies investigated the relationship between POS and employees' subjective well-being. The organizations who promote wellbeing of employees have more chances of positive attitude from its employees. Caesens et al. (2016) investigated the effect of weekly POS on employees' weekly subjective well-being at work in Belgium. Jain et al. (2013) investigated the moderating role of perceived organizational support (POS) in the relationship between stressors and citizenship behavior. Hur et al. (2015) also investigated the moderating role of POS in the relationship between emotional labor strategies and job-related outcomes (i.e. job satisfaction and job performance). Based on the same premise the previous research studies show that perceived organizational support is associated with many positive consequences. Based on this it can be hypothesized that:

H8. Perceived organizational support positively moderates the relationship between EI and employee well-being.

POS is not only associated with the extrinsic benefits of the employees like pays and financial rewards, but is also associated with the confidence, respect and association with the organization (Fuller et al., 2003). Saks (2006) stated that POS predicts employee engagement. Brunetto et al. (2013) investigated the effect of workplace relationships (perceived organizational support, supervisor' nurse relationships and teamwork) on the engagement, well-being, organizational commitment and turnover intentions of nurses working in Australian and USA hospitals. Their findings suggested that POS is a predictor of engagement. In respect of employees and organization association, employees with higher level of EI and employees who perceive higher levels of organizational support; allow employees to utilize their abilities to the best without feeling endangered about their self-esteem, social status, or profession. When employees experience psychological safety, they feel better about their job. Based on this it can be hypothesized that:

H9. Perceived organizational support positively moderates the relationship between EI and employees engagement.

\section{Methodology}

In the current study, positivistic quantitative approach has been used for hypotheses testing. Employees are the unit of analysis and data were collected through questionnaire survey among the employees of banking sector in Islamabad and Rawalpindi. Having infinite population, the study used the formula developed by Godden (2004) for the identification of reasonable sample size which turned out to be 384 . For data collection after stratifying the population simple random sampling technique has been used.

Stratified random sampling technique was used for data collection. Different strata of samples on the basis of their level such as OG3 and OG2 were made. After developing the strata, simple random sampling technique was applied for data collection. Data were obtained during the period of March 2016 and April 2016, from 450 employees.

450 questionnaires were distributed among employees, out of which only 395 usable questionnaires were returned, with the response rate of $81 \%$. Demographics included age, gender and education. Most of the respondents are below the age of 36 years $(80 \%)$, $71 \%$ of respondents are male and $58 \%$ respondents are having the degree of Master. 


\subsection{Instruments}

Emotional intelligence has been measured by the sixteen items scales of WLEIS developed by Wong and Law (2002); whereas, perceived organizational support was measured through the short version of Eisenberger et al. (1986). For the measurement of employee engagement nine item scale developed by Schaufeli and Bakker (2003) was employed. Well-being was measured using a four-item scale by Brunetto et al. (2012). For the measurement of turnover intentions four item scale developed by Bludern (1982) was used. The final version of the survey questionnaire was based on five point Likert scale.

\section{Results}

Table (1) shows the results of correlation statistics and the reliability of the variables.

The mean value of emotional intelligence is 3.36 , perceived organizational support is 3.35 , well-being is 3.06, employee's engagement is 3.46 and a turnover intention is 2.56. The standard deviation of emotional intelligence is 0.64 , perceived organizational support is 0.61 , well-being is 0.82 , employee's engagement is 0.80 and the SD of the turnover intention is .86, as per table
(1).

Emotional intelligence is positively correlated with perceived organizational support $\left(0.66^{* *}\right)$, well-being $\left(0.68^{* *}\right)$, employees engagement $\left(0.70^{* *}\right)$ and negatively correlated with turnover intentions $\left(-0.69^{* *}\right)$. Perceived organizational support is positively correlated with well-being $\left(0.70^{* *}\right)$, employees engagement $\left(0.64^{* *}\right)$ and negatively correlated with turnover intentions $\left(0.67^{* *}\right)$. Well-being is positively correlated with employees engagement $\left(0.46^{* *}\right)$ and negatively correlated with turnover intentions $\left(-.64^{* *}\right)$. Employees engagement negatively correlated with turnover intentions $\left(-.64^{* *}\right)$. The level of significant reliability is 0.70 which is recommended by Nunnally (1978) and this level was also recommended by Ndubisi (2006). The reliability of Emotional intelligence is (.817) perceived organizational support (.83), well-being (.82), employees engagement (.72) and negatively correlated with turnover intentions (.70).

Results of KMO and Bartlett's test reveals that variables are highly significant and principal component analysis was suitable for data shown in table 2.

Hypothesis 1 stated that emotional intelligence has a negative impact on turnover intentions. The result shows that emotional intelligence negatively associated with turnover intentions $(\mathrm{p}=.000$ less than $.05, \beta=-$

Table 1: Correlation, Descriptive Statistics and Reliability

\begin{tabular}{lccccccc}
\hline & Mean & SD & EI & POS & WB & EE & TOI \\
\hline EI & 3.36 & .64 & $(.817)$ & & & & \\
POS & 3.35 & .61 & $.655^{* *}$ & $(.838)$ & & & \\
WB & 3.06 & .82 & $.677^{* *}$ & $.702^{* *}$ & $(.828)$ & & \\
EE & 3.46 & .80 & $.695^{* *}$ & $.639^{* *}$ & $.468^{* *}$ & $(.723)$ & \\
TOI & 2.56 & .86 & $-.687^{* *}$ & $-.675^{* *}$ & $-.647^{* *}$ & $-.637^{* *}$ & $(.695)$ \\
\hline
\end{tabular}

${ }^{* *}$ Correlation is significant at the 0.01 level (2-tailed). $N=395$.

$E I=$ emotional intelligence, $P O S=$ perceived organizational support, $W B=$ well-being,

$E E=$ employee engagement, $T O I=$ turnover intentions

Table 2: KMO and Bartlett's Test

\begin{tabular}{llc}
\hline Kaiser-Meyer-Olkin & $\begin{array}{l}\text { Measure of Sampling } \\
\text { Adequacy }\end{array}$ & .851 \\
\hline Bartlett's Test & Approx. Chi Square & 2103.872 \\
of Sphericity & & \\
& Df & 91 \\
& Sig. & 0.000 \\
\hline
\end{tabular}


Table 3: Rotated component matrix

\begin{tabular}{|c|c|c|c|c|c|}
\hline & \multicolumn{5}{|c|}{ Component } \\
\hline & 1 & 2 & 3 & 4 & 5 \\
\hline EM1 & .675 & & & & \\
\hline EM2 & & & & & \\
\hline EM3 & .725 & & & & \\
\hline EM4 & & & & & \\
\hline EM5 & & & & & \\
\hline EM6 & .747 & & & & \\
\hline EM7 & .459 & & & & \\
\hline EM8 & .633 & & & & \\
\hline EM9 & .784 & & & & \\
\hline EM10 & .849 & & & & \\
\hline EM11 & .598 & & & & \\
\hline EM12 & .517 & & & & \\
\hline EM13 & & & & & \\
\hline EM14 & & & & & \\
\hline EM15 & .498 & & & & \\
\hline EM16 & & & & & \\
\hline POS1 & & & .438 & & \\
\hline POS2 & & & .611 & & \\
\hline POS3 & & & .804 & & \\
\hline POS4 & & & .821 & & \\
\hline POS5 & & & .585 & & \\
\hline POS6 & & & .612 & & \\
\hline POS7 & & & .823 & & \\
\hline POS8 & & & .666 & & \\
\hline WB1 & & .652 & & & \\
\hline WB2 & & .597 & & & \\
\hline WB3 & & .642 & & & \\
\hline WB4 & & .442 & & & \\
\hline EE1 & & & & & \\
\hline EE2 & & & & & .737 \\
\hline EE3 & .618 & & & & \\
\hline EE4 & .483 & & & & \\
\hline EE5 & .746 & & & & \\
\hline EE6 & .684 & & & & \\
\hline EE7 & .662 & & & & \\
\hline EE8 & .938 & & & & \\
\hline EE9 & & & & & \\
\hline TOI1 & & & & & .508 \\
\hline TOI2 & & & & & .489 \\
\hline TOI3 & & & & & .538 \\
\hline TOI4 & & & & & 0.602 \\
\hline
\end{tabular}

Extraction Method: Principal Component Analysis. Rotation Method: Varimax with Kaiser Normalization.a. Rotation converged in 43 iterations.

.65), which substantiated the hypothesis 1. These re- 2003; Firth et al., 2004; Goleman, 1998; Lee and Liu, sults are in accordance with pervious study (Carmeli, 2007). 


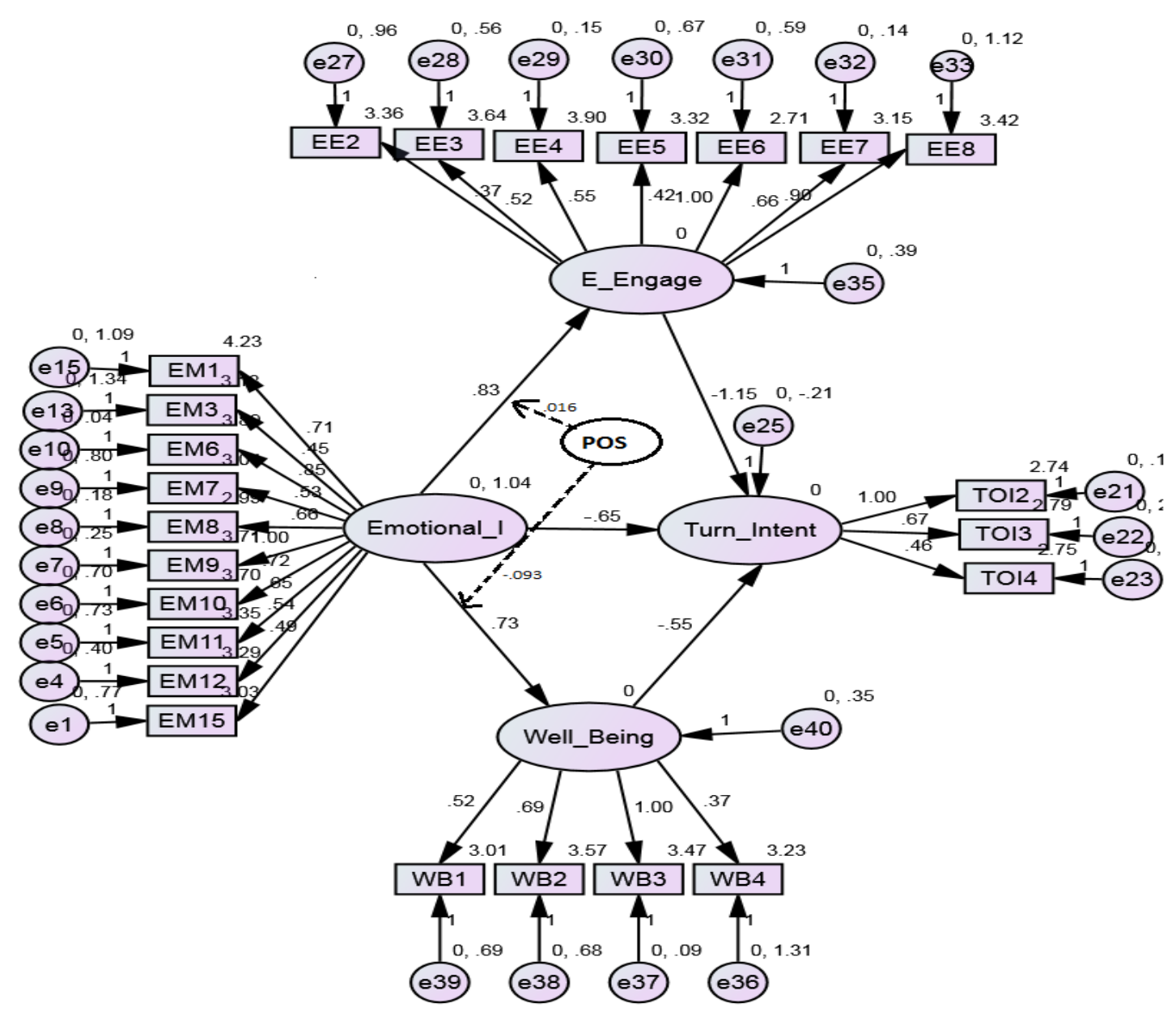

Figure 2: Path diagram.

Hypothesis 2 stated that emotional intelligence has a positive impact on employee well-being. The results shows that emotional intelligence have positive impact on employee well-being ( $\mathrm{p}=.000$ less than $.05, \beta=.73$ ). So our hypothesis two was substantiated. These result are according with pervious study (Ciarrochi et al., 2000; Goleman, 1995; Salovey and Mayer, 1990; Salovey et al., 1995).

Hypothesis 5 stated that EI have positive impact on employee engagement. The results shows that EI have positive impact on employee engagement ( $p=.000$ less than $.05, \beta=.83$ ). So our hypothesis five was substantiated. These results are also in accordance with pervious study (Pena Garrido and Extremera Pacheco, 2012; Saks, 2006; Zhu et al., 2015).

Results show that employee engagement mediates the relationship between emotional intelligence and turnover intentions in banking sector. Because emotional intelligence $(\mathrm{p}=0.000, \beta-.65)$ negatively impacts turnover intentions. Employee engagement $(p=0.000$, $\beta$-1.15) mediates the relationship between emotional intelligence $(p=0.000)$ and turnover intentions. So hypothesis 6 and 7 were substantiated. If banking sectors employees are highly emotionally intelligent then their engagement level is high from their jobs, subsequently decreasing their intentions to quit. And if employees have low emotional intelligence, then their engagement level is low, leading to higher intentions to quit. Path analysis was also run. Figure 2 show that Emotional intelligence has a positive effect on well-being and engagement, and negative effect on turnover intentions. Moreover, well-being and engagement have negative effect on turnover intentions. Therefore, well-being and engagement mediate the relationship between EI and turnover intentions.

Results also show that employee well-being mediates the relationship between emotional intelligence and turnover intentions in banking sector. Because emotional intelligence $(\mathrm{p}=0.000, \beta-.65)$ negatively impact on turnover intentions. Employee well-being ( $p$ $=0.000)$ mediates the relationship between emotional intelligence ( $\mathrm{p}=0.000, \beta-.55)$ and turnover intentions. So our hypothesis 3 and 4 were substantiated. If banking sectors employees are highly emotional intelligent then their well-being (satisfied) level is high from their jobs then their intentions to quit are low. And if employees have low emotional intelligent then their wellbeing (satisfied) level is low from their jobs then their 
Table 4: Standard estimation of the main Model

\begin{tabular}{llll}
\hline Standard Regression Weights & S.E. & C.R. & P \\
\hline H2 Well_Being <-Emotional_I & 0.73 & 3.26 & 0.000 \\
H1 Turn_Intent $<$-Emotional_I & -0.65 & 2.34 & 0.000 \\
H5 E_Engage $<-$ Emotional_I & 0.83 & 4.56 & 0.000 \\
H3 Turn_Intent $<-$ Well_Being & -0.55 & 3.45 & 0.000 \\
H6 Turn_Intent $<-$ E_Engage & -1.15 & 4.17 & 0.000 \\
H4 Turn_Intent $<-$ Well_Being<-Emotional_I & & & 0.000 \\
H7 Turn_Intent $<-$ E_Engage $<-$ Emotional_I & & & 0.000 \\
\hline
\end{tabular}

Table 5: Fit measures

\begin{tabular}{lc}
\hline Fit measure & Main Model \\
\hline X2 & 85.064 \\
Degree of Freedom(df) & 38 \\
Root Mean Square Residual(RMR) & 0.049 \\
Goodness-of-fit Index(GFI) & 0.9678 \\
Adjusted Goodness-of-fit Index(AGFI) & 0.944 \\
Comperative Fit Index(CFI) & 0.97 \\
Root Mean Square Error of Approximation (RMSEA) & 0.049 \\
\hline
\end{tabular}

GFI: The goodness of fit index, tells you what proportion of the variance in the sample variance covariance matrix is accounted for by the model. This should exceed 0.9 for a good model. AGFI: Adjusted GFI is an alternate GFI index in which the value of the index is adjusted for the number of parameters in the model. Few numbers of parameters in the model relative to the number of data points.

The structural equation model was examined to test the relationship among constructs. Goodness of fit indicates for this model were GFI $=0.9678, A G F I=0.944, C F I=0.97, R M R=0.0497$. Figure 1.1 depicts the full model. Of the 6 paths hypothesized in the model, all the paths were significant at $p ; 0.01$.

Table 6: Moderating role of perceived organizational support

\begin{tabular}{|c|c|c|c|c|c|c|}
\hline \multirow[t]{2}{*}{ Predictor } & \multicolumn{3}{|c|}{ Dependent: WB } & \multicolumn{3}{|c|}{ Dependent: EE } \\
\hline & Beta & $R^{2}$ & $\Delta R^{2}$ & Beta & $R^{2}$ & $\Delta R^{2}$ \\
\hline \multicolumn{7}{|l|}{ Moderation: POS } \\
\hline \multicolumn{7}{|l|}{ Step 1} \\
\hline Control variables & $.13^{* * *}$ & 0.39 & & $.161^{* * *}$ & 0.001 & \\
\hline \multicolumn{7}{|l|}{ Step 2} \\
\hline $\mathrm{E}$ & $.315^{* * *}$ & 0.86 & 0.47 & $.635^{* * *}$ & 0.88 & 0.87 \\
\hline POS & $.392^{* * *}$ & & & $.340^{* *}$ & & \\
\hline \multicolumn{7}{|l|}{ Step 3} \\
\hline Interaction term & $-.093^{* * *}$ & 0.9 & 0.04 & $.016^{* * *}$ & 0.89 & 0.01 \\
\hline
\end{tabular}

intentions to quit are high. 


\subsection{Moderating role of perceived organiza- tional support}

Perceived organizational support moderates the relationship between independent (emotional intelligence) and dependents variables (well-being, employees engagement). We perform each moderation analysis one by one.

To test $\mathrm{H} 8$ we centered round all variables on their means. In step 2 we entered EI entered, in step 3 we entered EI and perceived organizational support together and in step 4 we entered interaction term EPOS (EI*POS) keeping employee well-being (WB) as dependent variable. Results in Table 5 revealed that EI and perceived organizational support are significant predictor of $\mathrm{WB}(\beta=0.315, \mathrm{p}=0.000$ to $\beta=0.392, \mathrm{p}=0.000)$ respectively. Value of $\beta$ shows that higher level of perceived organizational support, the WB will be even higher as results. By adding the interaction term we found $\left(\Delta R^{2}=0.04, \mathrm{p}=0.000<0.05\right)$ the $\mathrm{p}$ value are less than 0.05 and significant. So the hypothesis 8 is substantiated; i.e. perceived organizational support positively moderates the relationship between emotional intelligence and employee well-being.

To test $\mathrm{H} 9$ we centered round all variables on their means. In step 2 we entered EI entered, in step 3 we entered EI and perceived organizational support together and in step 4 we entered interaction term EPOS (EI*POS) keeping employee engagement (EE) as dependent variable. Results in Table 6 revealed that EI and perceived organizational support are significant predictor of $\operatorname{EE}(\beta=0.63, \mathrm{p}=0.000$ to $\beta=0.34, \mathrm{p}=0.000)$ respectively. Value of $\beta$ shows that higher level of perceived organizational support, the EE will be even higher as results. By adding the interaction term we found $(p=0.01<0.05)$ and the $p$ value is less than 0.05 and significant. So the hypothesis 9 was substantiated, i.e. perceived organizational support positively moderates the relationship between emotional intelligence and employee engagement.

\section{Conclusion}

Present study has four main objectives. First perceived organizational support positively moderates the EI and employee engagement relationship, secondly perceived organizational support positively moderates the EI and employee well-being relationship, thirdly employee engagement mediates the EI and turnover intentions relationship and lastly employee well-being mediates the EI and turnover intentions relationship.

The outcomes of the study are a proof for the nomological validation of the EI and workplace incivility perceptions constructs. Nomological validity refers to correlations between constructs in accordance with some established theory Cronbach and Meehl (1955).
Current study investigated the path relationship from banks employees' emotional intelligence to employee well-being, engagement and finally turnover intentions; and further investigated how perceived organizational support has interactional effect between EI and mediators (engagement and well-being). This article indicates that EI must be included in retention strategies because of its impact on employee's turnover intentions. The findings suggest that emotional intelligence level of banking sector employees in Islamabad affects their engagement and well-being level, and their engagement and well-being level have effects on their turnover intentions, while perceived organizational support has interactional affects on the relationship between EI, engagement and well-being. Present study highlight the complex role of EI plays in turnover intentions.

\subsection{Managerial implications}

The current research stated that EI may be effectively used in banking sector. It further throws light on the significance of monitoring of work experiences by banks employees and recognizes the effect of EI on employee's well-being (satisfaction) and engagement, which in turn influences their intention to leave. It also identifies the link between EI and turnover intentions. It is central to existing banking sector, as retaining most experiences, valuable and trained employees are important for achieving desired outcomes in banks. From research we can find that turnover can cost up-to 93 to 200 percent of leaving workers annual payments (Griffet\& Horn, 2001); and in customer service industries the rate of turnover is particularly high (Korczynski, 2002).

While making policies for human resource management practices, the EI aptitude of bank employees may be considered during hiring and development process. In order to enhance retention, wellbeing and employee engagement consequences might be weighed. Along with, resource effective services, the top management should also visualize the outcome of selection of highly emotionally intelligent employees; as there are more chances of them performing a few assignments in a better way. The management may also think about training bank employees in order to appreciate the manner in which their behavior affects other employees. The organizations must arrange training session for their employees how to manage their emotions at work (Parkinson and Totterdell, 1999; Totterdell and Parkinson, 1999). Their work has seen the difference between two main categories of strategies. One that deals with the current mood and challenges, like reappraisal or social support, the engagement strategy; on the other hand, diversion strategy that concentrates away from the existing condition like avoidance. The research concluded that participants who were told to 
make use of engagement strategies displayed more optimistic moods and were able to face emotional demands in a better way. The findings of the study suggest that by training workers on use of specified strategies for managing their emotion, may show positive results in future.

\subsection{Limitations and Future Directions}

Present study used cross sectional data for analysis; more variance could be found if our collected data were longitudinal in nature; as there is always a room for improvement. Present study investigated the effect of EI on employee's engagement, employee well-being and turnover intentions: perceived organizational support as a moderator between EI and mediating variables relationship (employee engagement, employee wellbeing), used simple random sampling method, limited sample size was used and was conducted in banking sector. The study needs to be more comprehensive and may be examined with larger sample size. More industries could have been studied and comparisons among different sectors emotional intelligence impact on employee engagement, employee well-being and turnover intentions may have been seen. More researchers may also study the mediating roles of Well-being and engagement in the relationship between EI and organizational outcomes (job performance, organizational citizenship behavior and job satisfaction).

\section{References}

Agrawal, N. and Khan, M. S. (2015). Roles of emotional intelligence and spirituality on employees well-being.

Bande, B., Fernández-Ferrín, P., Varela, J. A., and Jaramillo, F. (2015). Emotions and salesperson propensity to leave: The effects of emotional intelligence and resilience. Industrial Marketing Management, 44:142-153.

Bar-On, R. (1997). Baron emotional quotient inventory. Toronto: Multi-Health Systems.

Brunetto, Y., Teo, S. T., Shacklock, K., and Farr-Wharton, R. (2012). Emotional intelligence, job satisfaction, well-being and engagement: explaining organisational commitment and turnover intentions in policing. Human Resource Management Journal, 22(4):428-441.

Brunetto, Y., Xerri, M., Shriberg, A., Farr-Wharton, R., Shacklock, K., Newman, S., and Dienger, J. (2013). The impact of workplace relationships on engagement, well-being, commitment and turnover for nurses in australia and the usa. Journal of Advanced Nursing, 69(12):2786-2799.

Caesens, G., Marique, G., Hanin, D., and Stinglhamber, F. (2016). The relationship between perceived organizational support and proactive behaviour directed towards the organization. European Journal of Work and Organizational Psychology, 25(3):398-411.
Carmeli, A. (2003). The relationship between emotional intelligence and work attitudes, behavior and outcomes: An examination among senior managers. Journal of managerial Psychology, 18(8):788-813.

Ciarrochi, J. V., Chan, A. Y., and Caputi, P. (2000). A critical evaluation of the emotional intelligence construct. Personality and Individual differences, 28(3):539-561.

Cronbach, L. J. and Meehl, P. E. (1955). Construct validity in psychological tests. Psychological bulletin, 52(4):281.

Cullen, K. L., Edwards, B. D., Casper, W. C., and Gue, K. R. (2014). Employees adaptability and perceptions of changerelated uncertainty: Implications for perceived organizational support, job satisfaction, and performance. Journal of Business and Psychology, 29(2):269-280.

Durán, A., Extremera, N., and Rey, L. (2004). Self-reported emotional intelligence, burnout and engagement among staff in services for people with intellectual disabilities. Psychological Reports, 95(2):386-390.

Eisenberger, R., Huntington, R., Hutchinson, S., and Sowa, D. (1986). Perceived organizational support. Journal of Applied Psychology, 71:500-507.

Firth, L., Mellor, D. J., Moore, K. A., and Loquet, C. (2004). How can managers reduce employee intention to quit? Journal of managerial psychology, 19(2):170-187.

Fuller, J. B., Barnett, T., Hester, K., and Relyea, C. (2003). A social identity perspective on the relationship between perceived organizational support and organizational commitment. The Journal of Social Psychology, 143(6):789-791.

Godden, B. (2004). Sample size formulas. Retrieved on December, 3:2013.

Goleman, D. (1995). Emotional intelligence, why it can matter more than iq. Technical report.

Goleman, D. (1998). Working with emotional intelligence bloomsbury.

Grant, A. M., Christianson, M. K., and Price, R. H. (2007). Happiness, health, or relationships? managerial practices and employee well-being tradeoffs. The Academy of Management Perspectives, 21(3):51-63.

Halbesleben, J. R. (2010). A meta-analysis of work engagement: Relationships with burnout, demands, resources, and consequences. Work engagement: A handbook of essential theory and research, 8:102-117.

Hur, W.-M., Han, S.-J., Yoo, J.-J., and Moon, T. W. (2015). The moderating role of perceived organizational support on the relationship between emotional labor and job-related outcomes. Management Decision, 53(3):605-624.

Jain, A., Giga, S., and Cooper, C. (2013). Perceived organizational support as a moderator in the relationship between organisational stressors and organizational citizenship behaviors. International Journal of Organizational Analysis, 21(3):313-334. 
Jordan, P. J. and Troth, A. (2011). Emotional intelligence and leader member exchange: The relationship with employee turnover intentions and job satisfaction. Leadership $\mathcal{E}$ Organization Development Journal, 32(3):260-280.

Karimi, L., Cheng, C., Bartram, T., Leggat, S. G., and Sarkeshik, S. (2015). The effects of emotional intelligence and stress-related presenteeism on nurses well-being. Asia Pacific Journal of Human Resources, 53(3):296-310.

Karimi, L., Leggat, S. G., Donohue, L., Farrell, G., and Couper, G. E. (2014). Emotional rescue: the role of emotional intelligence and emotional labour on well-being and job-stress among community nurses. Journal of advanced nursing, 70(1):176-186.

Korczynski, M. (2002). Human resource management in the service sector.

Kurtessis, J. N., Eisenberger, R., Ford, M. T., Buffardi, L. C., Stewart, K. A., and Adis, C. S. (2015). Perceived organizational support a meta-analytic evaluation of organizational support theory. Journal of Management, page 0149206315575554.

Lee, H.-W. and Liu, C.-H. (2007). An examination of factors affecting repatriates' turnover intentions. International Journal of manpower, 28(2):122-134.

Locke, E. (1976). The nature and cause of job satisfaction in dunnette, marvin d. Handbook of Industrial \& Organizational Psychology. Chicago: Raud McNally College Publishing Co.

Loi, R., Hang-Yue, N., and Foley, S. (2006). Linking employees' justice perceptions to organizational commitment and intention to leave: The mediating role of perceived organizational support. Journal of Occupational and Organizational Psychology, 79(1):101-120.

Mahon, E. G., Taylor, S. N., and Boyatzis, R. E. (2014). Antecedents of organizational engagement: exploring vision, mood and perceived organizational support with emotional intelligence as a moderator.

Mayer, J. (1997). What is emotional intelligence? en p. salovey y d. sluyter (eds.). emotional development and emotional intelligence: implications for educators (pp. 3-31).

Mayer, J. D., Salovey, P., Caruso, D. R., and Sitarenios, G. (2003). Measuring emotional intelligence with the msceit v2. 0. Emotion, 3(1):97.

Ndubisi, N. O. (2006). A structural equation modelling of the antecedents of relationship quality in the malaysia banking sector. Journal of Financial Services Marketing, 11(2):131141.

Nikolaou, I. and Tsaousis, I. (2002). Emotional intelligence in the workplace: Exploring its effects on occupational stress and organizational commitment. The International Journal of Organizational Analysis, 10(4):327-342.

Nunnally, J. (1978). Psychometric methods.
Parkinson, B. and Totterdell, P. (1999). Classifying affectregulation strategies. Cognition E Emotion, 13(3):277-303.

Pena Garrido, M. and Extremera Pacheco, N. (2012). Inteligencia emocional percibida en el profesorado de Primaria y su relación con los niveles de burnout e ilusión por el trabajo (engagement): Perceived Emotional Intelligence in Primary School Teachers and Its Relationship with Levels of Burnout and Engagement. Ministerio de Educación.

Por, J., Barriball, L., Fitzpatrick, J., and Roberts, J. (2011). Emotional intelligence: Its relationship to stress, coping, wellbeing and professional performance in nursing students. Nurse education today, 31(8):855-860.

Rahim, M. A., Civelek, I., and Liang, F. H. (2015). A model of department chairs' social intelligence and faculty members' turnover intention. Intelligence, 53:65-71.

Rousseau, D. (1995). Psychological contracts in organizations: Understanding written and unwritten agreements. Sage Publications.

Ryan, R. M. and Deci, E. L. (2001). On happiness and human potentials: A review of research on hedonic and eudaimonic well-being. Annual review of psychology, 52(1):141166.

Saks, A. M. (2006). Antecedents and consequences of employee engagement. Journal of managerial psychology, 21(7):600-619.

Salovey, P. and Mayer, J. D. (1990). Emotional intelligence. Imagination, cognition and personality, 9(3):185-211.

Salovey, P., Mayer, J. D., Goldman, S. L., Turvey, C., Palfai, T. P., et al. (1995). Emotional attention, clarity, and repair: Exploring emotional intelligence using the trait metamood scale. Emotion, disclosure, and health, 125:154.

Schaufeli, W. and Bakker, A. (2003). Utrecht work engagement scale: Preliminary manual. utrecht occupational health psychology unit, utrecht university.

Schutte, N. S., Malouff, J. M., Hall, L. E., Haggerty, D. J., Cooper, J. T., Golden, C. J., and Dornheim, L. (1998). Development and validation of a measure of emotional intelligence. Personality and individual differences, 25(2):167-177.

Sellgren, S., Ekvall, G., and Tomson, G. (2007). Nursing staff turnover: does leadership matter? Leadership in Health Services, 20(3):169-183.

Shuck, B. and Reio Jr, T. G. (2014). Employee engagement and well-being: A moderation model and implications for practice. Journal of Leadership E Organizational Studies, 21(1):43-58.

Siegrist, J. and Rödel, A. (2006). Work stress and health risk behavior. Scandinavian journal of work, environment $\mathcal{E}$ health, pages 473-481.

Slaski, M. and Cartwright, S. (2003). Emotional intelligence training and its implications for stress, health and performance. Stress and health, 19(4):233-239. 
Sy, T., Tram, S., and OHara, L. A. (2006). Relation of employee and manager emotional intelligence to job satisfaction and performance. Journal of vocational behavior, 68(3):461-473.

Thanacoody, P., Newman, A., and Fuchs, S. (2014). Affective commitment and turnover intentions among healthcare professionals: The role of emotional exhaustion and disengagement. The International Journal of Human Resource Management, 25(13):1841-1857.

Totterdell, P. and Parkinson, B. (1999). Use and effectiveness of self-regulation strategies for improving mood in a group of trainee teachers. Journal of occupational health psychology, $4(3): 219$.

Trivellas, P., Gerogiannis, V., and Svarna, S. (2011). The impact of emotional intelligence on job outcomes and turnover intention in health care. ICININFO-2011, Advances on Information Processing and Management (AIPM), $1: 356-360$.

Tsaousis, I. and Nikolaou, I. (2005). Exploring the relationship of emotional intelligence with physical and psychological health functioning. Stress and health, 21(2):77-86.
Weiss, H. M. (2002). Deconstructing job satisfaction: Separating evaluations, beliefs and affective experiences. Human resource management review, 12(2):173-194.

Wong, C.-S. and Law, K. S. (2002). The effects of leader and follower emotional intelligence on performance and attitude: An exploratory study. The leadership quarterly, 13(3):243-274.

Wright, T. A. and Cropanzano, R. (2000). Psychological wellbeing and job satisfaction as predictors of job performance. Journal of occupational health psychology, 5(1):84.

Wrzesniewski, A., Dutton, J. E., and Debebe, G. (2003). Interpersonal sensemaking and the meaning of work. Research in organizational behavior, 25:93-135.

Zhu, Y., Liu, C., Guo, B., Zhao, L., and Lou, F. (2015). The impact of emotional intelligence on work engagement of registered nurses: the mediating role of organisational justice. Journal of clinical nursing, 24(15-16):2115-2124. 